\title{
Qualitative data analysis: a practical example
}

\section{Helen Noble, ${ }^{1}$ Joanna Smith ${ }^{2}$}

\subsection{6/eb-2013-101603}

\section{${ }^{1}$ School of Nursing and Midwifery, Queens's University Belfast, Belfast, UK \\ ${ }^{2}$ Department of Health Sciences, University of Huddersfield, Huddersfield, UK}

\section{Correspondence to:}

Dr Helen Noble

School of Nursing and Midwifery, Queen's University Belfast, Medical Biology Centre, 97 Lisburn Road, Belfast BT9 7BL, UK; helen.noble@qub.ac.uk
The aim of this paper is to equip readers with an understanding of the principles of qualitative data analysis and offer a practical example of how analysis might be undertaken in an interview-based study.

\section{What is qualitative data analysis?}

Qualitative research is a generic term that refers to a group of methods, and ways of collecting and analysing data that are interpretative or explanatory in nature and focus on meaning. Data collection is undertaken in the natural setting, such as a clinic, hospital or a participant's home because qualitative methods seek to describe, explore and understand phenomena from the perspective of the individual or group. Reality is coconstructed by the research participants and the researcher, with the depth of data collected more important than recruiting large samples. The individual interview method is the most widely used method of data collection in qualitative research and a range of data can be collected including field notes, audio and video recordings, images or documents. Qualitative researchers usually work with text when analysing data; data can be transcribed in entirety or focus on selected sections. However, focusing on selected sections of the data may not capture the nuances of observations or participants' descriptions and may fragment the data. The challenge for qualitative researchers is to present a cohesive representation of the data, which can be 'vast' and 'messy', and needs to make sense of diverse viewpoints or complex issues. The process of data analysis is to assemble or reconstruct the data in a meaningful or comprehensible fashion, in a way that is transparent, rigorous and thorough, while remaining 'true' to participants' accounts.

\section{What are the approaches in undertaking qualitative data analysis?}

Although qualitative data analysis is inductive and focuses on meaning, approaches in analysing data are diverse with different purposes and ontological (concerned with the nature of being) and epistemological (knowledge and understanding) underpinnings. ${ }^{2}$ Identifying an appropriate approach in analysing qualitative data analysis to meet the aim of a study can be challenging. One way to understand qualitative data analysis is to consider the processes involved. ${ }^{3}$ Approaches can be divided into four broad groups: quasistatistical approaches such as content analysis; the use of frameworks or matrices such as a framework approach and thematic analysis; interpretative approaches that include interpretative phenomenological analysis and grounded theory; and sociolinguistic approaches such as discourse analysis and conversation analysis. However, there are commonalities across approaches. Data analysis is an interactive process, where data are systematically searched and analysed in order to provide an illuminating description of phenomena; for example, the experience of carers supporting dying patients with renal disease ${ }^{4}$ or student nurses' experiences following assignment referral. ${ }^{5}$ Data analysis is an iterative or recurring process, essential to the creativity of the analysis, development of ideas, clarifying meaning and the reworking of concepts as new insights 'emerge' or are identified in the data.

\section{Do you need data software packages when analysing qualitative data?}

Qualitative data software packages are not a prerequisite for undertaking qualitative analysis but a range of programmes are available that can assist the qualitative researcher. Software programmes vary in design and application but can be divided into text retrievers, code and retrieve packages and theory builders. ${ }^{6}$ NVivo and NUD*IST are widely used because they have sophisticated code and retrieve functions and modelling capabilities, which speed up the process of managing large data sets and data retrieval. Repetitions within data can be quantified and memos and hyperlinks attached to data. Analytical processes can be mapped and tracked and linkages across data visualised leading to theory development. ${ }^{6}$ Disadvantages of using qualitative data software packages include the complexity of the software and some programmes are not compatible with standard text format. Extensive coding and categorising can result in data becoming unmanageable and
Table 1 Data extract containing units of data and line-by-line coding

\begin{tabular}{|c|c|}
\hline Data extract (carer) units of data (in vivo codes highlighted) & $\begin{array}{l}\text { Early descriptive codes/line-by-line } \\
\text { coding }\end{array}$ \\
\hline $\begin{array}{l}\text { He (the doctor) said there was nothing more he could do for her. I said to him, } \\
\text { can't you give her dialysis? And he said, no because it would kill her. I suppose } \\
\text { it's too late in the day. I don't know. That's the reason he gave me, it would kill } \\
\text { her. } \\
\text { So I don't really know, but I thought well, why wait till there's only } 20 \% \text { function } \\
\text { left before you tell me in the first place. So shouldn't he have told me when she } \\
\text { could have had dialysis? Shouldn't someone then have said to me, well look, she } \\
\text { can have dialysis before it got to the stage where she suddenly has } 20 \% \text { of } \\
\text { function and she can't have it. Couldn't someone have mentioned it earlier? You } \\
\text { know what l'm trying to say? }\end{array}$ & $\begin{array}{l}\text { Nothing more they could do Wanting } \\
\text { dialysis } \\
\text { Treatment would kill } \\
\text { Too late to treat } \\
\text { Treatment would kill } \\
\text { Not being told early about prognosis/ } \\
\text { reduced kidney function } \\
\text { Not being involved in treatment decision/ } \\
\text { confusion* } \\
\text { Missed treatment opportunity? }\end{array}$ \\
\hline
\end{tabular}


researchers may find visualising data on screen inhibits conceptualisation of the data.

\section{How do you begin analysing qualitative data?}

Despite the diversity of qualitative methods, the subsequent analysis is based on a common set of principles and for interview data includes: transcribing the interviews; immersing oneself within the data to gain detailed insights into the phenomena being explored; developing a data coding system; and linking codes or units of data to form overarching themes/concepts, which may lead to the development of theory. ${ }^{2}$ Identifying recurring and significant themes, whereby data are methodically searched to identify patterns in order to provide an illuminating description of a phenomenon, is a central skill in undertaking qualitative data analysis. Table 1 contains an extract of data taken from a research study which included interviews with carers of people with end-stage renal disease managed without dialysis. The extract is taken from a carer who is trying to understand why her mother was not offered dialysis. The first stage of data analysis involves the process of initial coding, whereby each line of the data is considered to identify keywords or phrases; these are sometimes known as in vivo codes (highlighted) because they retain participants' words.

When transcripts have been broken down into manageable sections, the researcher sorts and sifts them, searching for types, classes, sequences, processes, patterns or wholes. The next stage of data analysis involves bringing similar categories together into broader themes. Table 2 provides an example of the early development of codes and categories and how these link to form broad initial themes.

Table 3 presents an example of further category development leading to final themes which link to an overarching concept.

\section{How do qualitative researchers ensure data analysis procedures are transparent and robust?}

In congruence with quantitative researchers, ensuring qualitative studies are methodologically robust is essential. Qualitative researchers need to be explicit in describing how and why they undertook the research. However, qualitative research is criticised for lacking

Table 2 Development of initial themes from descriptive codes

\begin{tabular}{ll}
\hline Early descriptive codes/categories & Broad initial theme \\
\hline Wanting dialysis & $\begin{array}{l}\text { The less informed } \\
\text { decision }\end{array}$ \\
$\begin{array}{l}\text { No benefit from treatments } \\
\text { Poor understanding of disease }\end{array}$ & \\
management & \\
Confusion about treatments & \\
Not sure about which treatment & \\
options to take & \\
Requiring further knowledge \\
Inadequate communication
\end{tabular}

Table 3 Development of final themes and overarching concept

\begin{tabular}{lll}
\hline $\begin{array}{l}\text { Category } \\
\text { development }\end{array}$ & Final themes & $\begin{array}{l}\text { Overarching } \\
\text { concepts }\end{array}$ \\
\hline $\begin{array}{l}\text { Arduous nature of } \\
\text { dialysis }\end{array}$ & $\begin{array}{l}\text { Informed and } \\
\text { autonomous } \\
\text { decisions }\end{array}$ & $\begin{array}{l}\text { The patients' } \\
\text { decision }\end{array}$ \\
$\begin{array}{l}\text { Difficulties in getting } \\
\text { Previous experience } \\
\text { of dialysis }\end{array}$ & \\
$\begin{array}{l}\text { Age as a reason not } \\
\text { to start dialysis }\end{array}$ & \\
$\begin{array}{l}\text { Uncertainty about } \\
\text { treatment options }\end{array}$ & Less informed \\
Not involved in \\
treatment decisions* \\
$\begin{array}{l}\text { Poor understanding } \\
\text { of disease } \\
\text { management }\end{array}$ \\
$\begin{array}{l}\text { Confusion about } \\
\text { treatments }\end{array}$
\end{tabular}

*This early description can be tracked through the following tables, essential in demonstrating transparency.

transparency in relation to the analytical processes employed, which hinders the ability of the reader to critically appraise study findings. ${ }^{7}$ In the three tables presented the progress from units of data to coding to theme development is illustrated. 'Not involved in treatment decisions' appears in each table and informs one of the final themes. Documenting the movement from units of data to final themes allows for transparency of data analysis. Although other researchers may interpret the data differently, appreciating and understanding how the themes were developed is an essential part of demonstrating the robustness of the findings. Qualitative researchers must demonstrate rigour, associated with openness, relevance to practice and congruence of the methodological approch. ${ }^{2}$ In summary qualitative research is complex in that it produces large amounts of data and analysis is time consuming and complex. High-quality data analysis requires a researcher with expertise, vision and veracity.

Competing interests None.

\section{References}

1. Lee B A real life guide to accounting research: a behind the scenes view of using qualitative research methods. Amsterdam: Elsevier, 2004.

2. Morse JM, Richards L. Read me first for a user's guide to qualitative methods. London: Sage Publications, 2002.

3. Smith J, Cheater F, Bekker H. Theoretical versus pragmatic design challenges in qualitative research. Nurse Res 2011;18:39-51.

4. Noble H, Kelly D, Hudson P. Experiences of carers supporting dying renal patients, managed without dialysis. $J$ Adv Nurs 2013;69:1829-39.

5. Robshaw M, Smith J. Keeping afloat: student nurses' experiences following assignment referral. Nurse Educ Today 2004;24:511-20

6. McLafferty E, Farley AH. Analysing qualitative data using computer software. Nurs Times 2006;102:34-6.

7. Maggs-Rapport F. 'Best research practice': in pursuit of methodological rigour. J Adv Nurs 2001;35:373-87. 